\title{
The synthesis of sulfur-doped carbon nanofibers using chemical vapor deposition on the nickel-ferrite catalyst and the gold decoration of the product for morphine sensing
}

\author{
Hossein Tavakol ${ }^{1}$ (D) Sina Salimpour ${ }^{1} \cdot$ Willi Salvenmoser $^{2}$
}

Received: 20 June 2020 / Accepted: 29 October 2020 / Published online: 19 November 2020

(c) Springer Nature Switzerland AG 2020

\begin{abstract}
Sulfur-doped carbon nanofibers (SCNFs) were prepared using chemical vapor deposition. In this line, different catalysts and various growth temperatures have been examined to obtain the optimized conditions. Among the employed catalysts, $\mathrm{NiFe}_{2} \mathrm{O}_{4}$ showed the most performance, and the best quality of the prepared SCNFs was $600{ }^{\circ} \mathrm{C}$. To enhance the electrochemical behaviors, the prepared SCNFs was decorated with gold nanoparticles using electrochemical deposition. Both products (doped and undoped) were fully characterized using common methods. Then, they used for the electrochemical detection of morphine using cyclic voltammetry and square wave voltammetry. The obtained electrochemical diagrams demonstrated the high efficiency of the synthesized product for sensing of morphine.
\end{abstract}

Keywords Carbon $\cdot$ Nanofibers $\cdot$ Sulfur $\cdot$ CVD $\cdot$ Morphine $\cdot$ Sensor

\section{Introduction}

Nanomaterials, especially carbon nanomaterials, have been attracted broad interests in the recent decades because of their promising properties and vast applications. There are several types of nanostructures for carbon materials, such as fullerenes, nanotubes and nanofibers [1]. Carbon nanofibers (CNFs) could be produced using the decomposition of organic compounds on a metal or metal-based catalyst [2]. The exclusive structure of CNFs makes them appropriate candidates for different applications such as electronic materials, hydrogen storage, catalyst, sensors and catalytic supports [3]. Various CNFs (twisted, straight or spiral) could be prepared by employing various carbon sources, catalysts or preparation methods. Typically, the CNFs diameters mostly are between 3 and $100 \mathrm{~nm}$, while their lengths usually are in the range of $0.1-100 \mathrm{~mm}$ [4].

The doping of heteroatom has been widely employed for the modification of carbon materials [5]. In this line, several protocols have been applied for the insertion of heteroatoms in the structure of carbon nanomaterials. Recent reports have demonstrated that heteroatom doping can dramatically influence the structures and properties of CNFs. Moreover, the use of different catalysts (Fe, $\mathrm{Mo}, \mathrm{Ni}$ ) has been reported to prepare these materials. In recent years, nanoscale ferrites $\left(\mathrm{MFe}_{2} \mathrm{O}_{4}\right)$ have been prepared increasingly because of their interesting physical properties [6]. All ferrites have moderate magnetic properties and n-type semi-conductivity that propose a wide range of applications for them [7]. There are several reports on the growth of simple and doped CNFs by the Electronic supplementary material The online version of this article (https://doi.org/10.1007/s42452-020-03789-6) contains
supplementary material, which is available to authorized users.

$\triangle$ Hossein Tavakol, h_tavakol@iut.ac.ir | ${ }^{1}$ Department of Chemistry, Isfahan University of Technology, Isfahan 84156-83111, Iran. ${ }^{2}$ Institute for Zoology and CMBI, University of Innsbruck, Technikerstrasse 25, A-6020 Innsbruck, Austria. 
chemical vapor deposition (CVD) method, while none of them has been used ferrites as catalysts for the preparation of S-doped CNFs (SCNFs).

Furthermore, the effect of different metal catalysts ( $\mathrm{Ni}$, $\mathrm{Fe}, \mathrm{Co})[8]$, catalyst support ( $\mathrm{MgO}, \mathrm{SiO}_{2}, \mathrm{Al}_{2} \mathrm{O}_{3}$ and $\mathrm{TiO}_{2}$ ) [9], carbon source (methane, ethane and carbon monoxide) [10], and the reaction conditions on the yield of CNFs have been investigated. Mostly $\mathrm{Ni}$, Co and Fe have been employed for the CNFs' growth both as bulk particles (with the typical size of $700 \mathrm{~nm}$ ) and as supported particles $(10-50 \mathrm{~nm})$. These metals have been used to form their carbides, which produces carbon nanostructures [11]. Moreover, besides the Ni-based catalysts, which need fewer temperatures and give higher yields, the activity of other metals (W, Cu, Cr and Mo) has been investigated [12].

After the preparation of these carbon materials, they could be used in various applications. In this work, we have focused on the sensor properties of this type of material to detect morphine. Morphine is the most abundant alkaloid in opium, the most effective painkiller and a synthetic intermediate for the preparation of various related drugs [13]. Therefore, the determination of this compound in pharmaceutical and biological samples could be significant [14]. Measuring morphine could be performed using different analytical methods such as thin-layer chromatography, GC [15], Mass spectrometry [16], HPLC [17], surface plasmon resonance [18], UV-Vis spectroscopy [19], fluorimetry [20], chemiluminescence [21], radioimmunoassay (RIA) [22], and electrochemical methods [23]. Therefore, the use of the prepared SCNF as a morphine sensor has been considered in this study. In this line, gold-decoration on the surface of SCNFs has also been investigated [24-27].

The use of various ferrites in the preparation of CNTs has been reported by Dhand et al. using CVD method [28]. Based on the reported studies and previous investigations of this group, among various possible catalysts for preparing these materials, ferrites showed the highest efficiency in the preparation of SCNFs. They showed $\mathrm{Zn}$ and Co ferrites could not perform the desired product in $700^{\circ} \mathrm{C}$ and led to spherical carbons. In this work, based on the work of Dhand and the previous experiences of this group on the sulfur doping and decoration of carbon nanostructures [29-31], sulfur-doped nanofibers (SCNFs) have been synthesized via the CVD method and decorated with gold nanoparticles (GNPs) by electrodeposition. This doping has been considered because of the strong interaction between sulfur and gold and its intense effects on carbon materials (based on our previous studies). The selection of gold has been made because there are a few reports on the electrochemical behaviors of gold-decorated carbon nanomaterials and this element has the highest stability among all metals of the periodic table.

\section{Experimental}

Inorganic salts, including $\mathrm{FeCl}_{3} \cdot 6 \mathrm{H}_{2} \mathrm{O}, \mathrm{NiCl}_{2} \cdot 6 \mathrm{H}_{2} \mathrm{O}$ and $\mathrm{ZnCl}$. were purchased from Merck and used without further purification. Other chemicals such as ethanol, oleic acid, ammonia, sulfur and hydrochloric acid were bought from domestic companies in industrial grade and used after purification. The acetylene (99.99\%) and argon (99.9999\%) gases were prepared from Tebgas Company (Isfahan, Iran). A double-zone electric tube furnace (Nano sat $\mathrm{Co}$, Semnan, Iran; www.nanosatco.com) has been employed to grow products. The reaction chamber was a horizontal tube (quartz) of $45 \mathrm{~mm}$ diameter and $120 \mathrm{~cm}$ length. The morphology of the samples and EDS analyses were determined using MIRA3 TESCAN FESEM with. A Philips X-ray diffractometer was used to obtain the XRD patterns. Raman spectra were recorded using Takram P50C0R10 spectrometer. IR spectra were recorded on a JASCO FTIR680 plus spectrometer. The reflectance spectra were recorded on JASCO V570 spectrophotometer. The electrochemical experiments were performed using Autolab potentiostat/ galvanostat (Metrohm system) containing a GCE, Pt and $\mathrm{Ag} / \mathrm{AgCl}$ electrodes. The Britton-Robinson buffer solution was prepared by mixing equimolar amounts of $0.04 \mathrm{M}$ of phosphoric acid, boric acid and acetic acid. The $\mathrm{pH}$ was corrected using $0.01 \mathrm{M}$ sodium hydroxide solution.

\subsection{Synthesis of spinel ferrites}

\subsubsection{Synthesis of $\mathrm{NiFe}_{2} \mathrm{O}_{4}$}

All Spinel Ferrites $\mathrm{MFe}_{2} \mathrm{O}_{4}$ nanoparticles $(\mathrm{M}=\mathrm{Ni}, \mathrm{Ni} /$ $\mathrm{Zn}$, and $\mathrm{Zn}$ ) were synthesized by the co-precipitation method, as previously reported method [32]. For the synthesis of $\mathrm{NiFe}_{2} \mathrm{O}_{4}, \mathrm{NiCl}_{2} \cdot 6 \mathrm{H}_{2} \mathrm{O}(2.4)$ and $\mathrm{FeCl}_{3} \cdot 6 \mathrm{H}_{2} \mathrm{O}(5.4 \mathrm{~g})$ were added to deionized water $(50 \mathrm{~mL})$ in a $100 \mathrm{~mL}$ round-bottom flask with mechanical stirring at $60^{\circ} \mathrm{C}$ for a few minutes. The solution was deoxygenated by introducing argon gas and then, $2 \mathrm{~mL}$ oleic acid was added. After this step, aqueous ammonia (25\%) was added to the solution until $\mathrm{pH}=8-9$. The suspension was stirred for one $\mathrm{h}$ at $80^{\circ} \mathrm{C}$ and cooled to room temperature. The precipitates were separated, rinsed with deionized water (3 times) and $\mathrm{EtOH}$ ( 2 times) and dried for $12 \mathrm{~h}$.

\subsubsection{Synthesis of $\mathrm{ZnFe}_{2} \mathrm{O}_{4}$}

Briefly, using $1.4 \mathrm{~g}$ of $\mathrm{ZnCl}_{2}$ instead of $\mathrm{NiCl}_{2} \cdot 6 \mathrm{H}_{2} \mathrm{O}$ as raw material, $\mathrm{ZnFe}_{2} \mathrm{O}_{4}$ nanoparticles were prepared based on the above method. 


\subsubsection{Synthesis of $\mathrm{Ni}_{0.5} \mathrm{Zn}_{0.5} \mathrm{Fe}_{2} \mathrm{O}_{4}$}

According to the above method, $1.2 \mathrm{~g}$ of $\mathrm{NiCl}_{2} \cdot 6 \mathrm{H}_{2} \mathrm{O}, 0.7 \mathrm{~g}$ of $\mathrm{ZnCl}_{2}$ and $5.4 \mathrm{~g}$ of $\mathrm{FeCl}_{3} \cdot 6 \mathrm{H}_{2} \mathrm{O}$ were used instead of $\mathrm{NiCl} \cdot 6 \mathrm{H}_{2} \mathrm{O}$ for the preparation of $\mathrm{Ni}_{1 / 2} \mathrm{Zn}_{1 / 2} \mathrm{Fe}_{2} \mathrm{O}_{4}$ synthesis.

\subsection{Synthesis and purification of SCNFs}

$100 \mathrm{mg}$ of the employed catalyst was distributed on a ceramic boat, which was placed in the second heating zone of CVD. SCNFs were synthesized by decomposition of acetylene gas on the prepared catalyst, while $1.5 \mathrm{~g}$ of sulfur powder (in a ceramic boat) was placed in the first heating zone. The second zone'e temperature was reached to $600^{\circ} \mathrm{C}$ while the sulfur container temperature ( 1 st zone) was changed from room temperature to $200^{\circ} \mathrm{C}$ in an argon atmosphere. Then, in SCNFs growth stage, the temperature of the second zone was kept constant. Subsequently, the sulfur container temperature (1st zone) was raised to $550^{\circ} \mathrm{C}$. In this step, the $50 \%$ argon flow was replaced by acetylene $(150 \mathrm{~mL} / \mathrm{min})$ for $45 \mathrm{~min}$. Then, the substrates were cooled slowly to room temperature in argon ambient and SCNFs are collected as a black powder. The product was purified simply by washing with concentrated hydrochloric acids for catalyst removal and washed with distilled water several times.

\subsection{Electrochemical analyses}

$5.0 \mathrm{mg}$ of prepared SCNFs was dispersed in DMF (1 mL) with sonication for $15 \mathrm{~min}$. Before the modification of the glassy carbon electrode (GCE), it has been prepared by polishing, washing and drying. The GCE was modified with SCNFs by micro-injecting the SCNFs suspension $(3 \mu \mathrm{L})$ on a fresh GCE and drying at room temperature for $24 \mathrm{~h}$ to prepare SCNFs/GCE. Further modification of SCNFs/GCE was followed by the electrodeposition of gold nanoparticles, using cyclic voltammetry (CV) (12 cycles) in -1.00 to $0.50 \mathrm{~V}$ with $50 \mathrm{mV} / \mathrm{S}$ scan rate, from a solution containing $1 \times 10^{-4}$ $\mathrm{M} \mathrm{HAuCl}_{4}$ prepared in $0.01 \mathrm{M} \mathrm{KCl}$, which prepared in double-distilled water. Then, the fabricated AuNPs/SCNFs/GCE electrode was rinsed with deionized water and dried. The cyclic voltammogram for electrochemical deposition of gold nanoparticles on SCNFs/GCE has shown in Fig. S1.

\section{Results and discussion}

\subsection{Characterization of spinel ferrites (catalysts)}

The structures of spinel ferrites, $\mathrm{NiF}_{2} \mathrm{O}_{4}, \mathrm{Ni}_{0.5} \mathrm{Zn}_{0.5} \mathrm{Fe}_{2} \mathrm{O}_{4}$ and $\mathrm{ZnFe}_{2} \mathrm{O}_{4}$, were examined by FT-IR and UV-Vis spectroscopy, as shown in Fig. S2 in supporting information. These materials were synthesized based on the previous reports and we used only these simple experiments to confirm our procedure's correctness. In the FT-IR spectra, the ferrites' absorption bands are in good agreement with previously reported results [33]. The absorption band at $692 \mathrm{~cm}^{-1}$ shows Fe-O stretching in a tetrahedron and at $472 \mathrm{~cm}^{-1}$ is related to that vibration at octahedral structure. These absorption peaks are typical signals showing the structure of inverse spinel ferrites [34].

Figure $\mathrm{S} 2$ in the Supporting Information shows the UV-Vis diffuse reflectance spectroscopy (DRS) of $\mathrm{NiF}_{2} \mathrm{O}_{4}$, $\mathrm{Ni}_{0.5} \mathrm{Zn}_{0.5} \mathrm{Fe}_{2} \mathrm{O}_{4}$ and $\mathrm{ZnFe}_{2} \mathrm{O}_{4}$ nanoparticles. Some absorption bands (at 296, 284 and $282 \mathrm{~nm}$ ) have been observed for these nanoparticles. This future is related to ${ }^{6} \mathrm{~A}_{1} \rightarrow{ }^{4} \mathrm{~T}_{2}$ $\left({ }^{4} G\right)$ transition for the ferric ion [35].

\subsection{Synthesis and characterization of SCNFs}

For each CVD experiment, there are several minor parameters (flow rates of carrier and reagent gases, temperature program for heating and cooling steps, the value of catalyst ...) that generally should be optimized in the preliminary experiments. After obtaining the optimized minor parameters, the growth temperature should be optimized as a major parameter. Based on the previous experiment, two temperatures, 600 and $800{ }^{\circ} \mathrm{C}$, were used for the growth step using zinc ferrite catalyst. Moreover, three different ferrites $\left(\mathrm{NiF}_{2} \mathrm{O}_{4}, \mathrm{Ni}_{0.5} \mathrm{Zn}_{0.5} \mathrm{Fe}_{2} \mathrm{O}_{4}\right.$ and $\left.\mathrm{ZnFe}_{2} \mathrm{O}_{4}\right)$ have been examined to obtain the best catalyst for this process. Therefore, four experiments were designed to optimize these parameters and the obtained products were analyzed using FESEM, EDS and Raman analyses. In these experiments, $\mathrm{NiFe}_{2} \mathrm{O}_{4}$ at $600{ }^{\circ} \mathrm{C}, \mathrm{Ni}_{0.5} \mathrm{Zn}_{0.5} \mathrm{Fe}_{2} \mathrm{O}_{4}$ at $600{ }^{\circ} \mathrm{C}, \mathrm{ZnFe}_{2} \mathrm{O}_{4}$ at $600{ }^{\circ} \mathrm{C}$ and $\mathrm{ZnFe}_{2} \mathrm{O}_{4}$ at $800{ }^{\circ} \mathrm{C}$ (respectively a to d) have been chosen as the growth's catalyst and temperature.

By observing these images (Fig. 1a-c) and based on the product's morphology, the catalytic activities of applied ferrites at $600{ }^{\circ} \mathrm{C}$ for the preparation of SCNFs have not meaningful differences. The external diameters of the obtained products are about $100 \mathrm{~nm}$ (Fig. 1a-c). Based on the type of ferrite surface, the product's morphology has been changed. In the SCNFs obtained with $\mathrm{NiF}_{2} \mathrm{O}_{4}$ catalysts (Fig. 1a), the fibers' diameters are more homogeneous. It is clearly visible from the images of grown SCNFs on $\mathrm{ZnFe}_{2} \mathrm{O}_{4}$ (Fig. 1c) that two shapes could be observed for the product. The first shape has $35 \mathrm{~nm}$ diameter and the second shape has 500-600 nm diameters. As previously demonstrated by Dhand et al., the rising of growth temperature from 600 to $700{ }^{\circ} \mathrm{C}$, could change the morphology of grown carbon on the ferrites' surface [36]. Figure 1d shows only the spherical carbon particles with approximately 500-700 nm diameters. These spherical carbons 

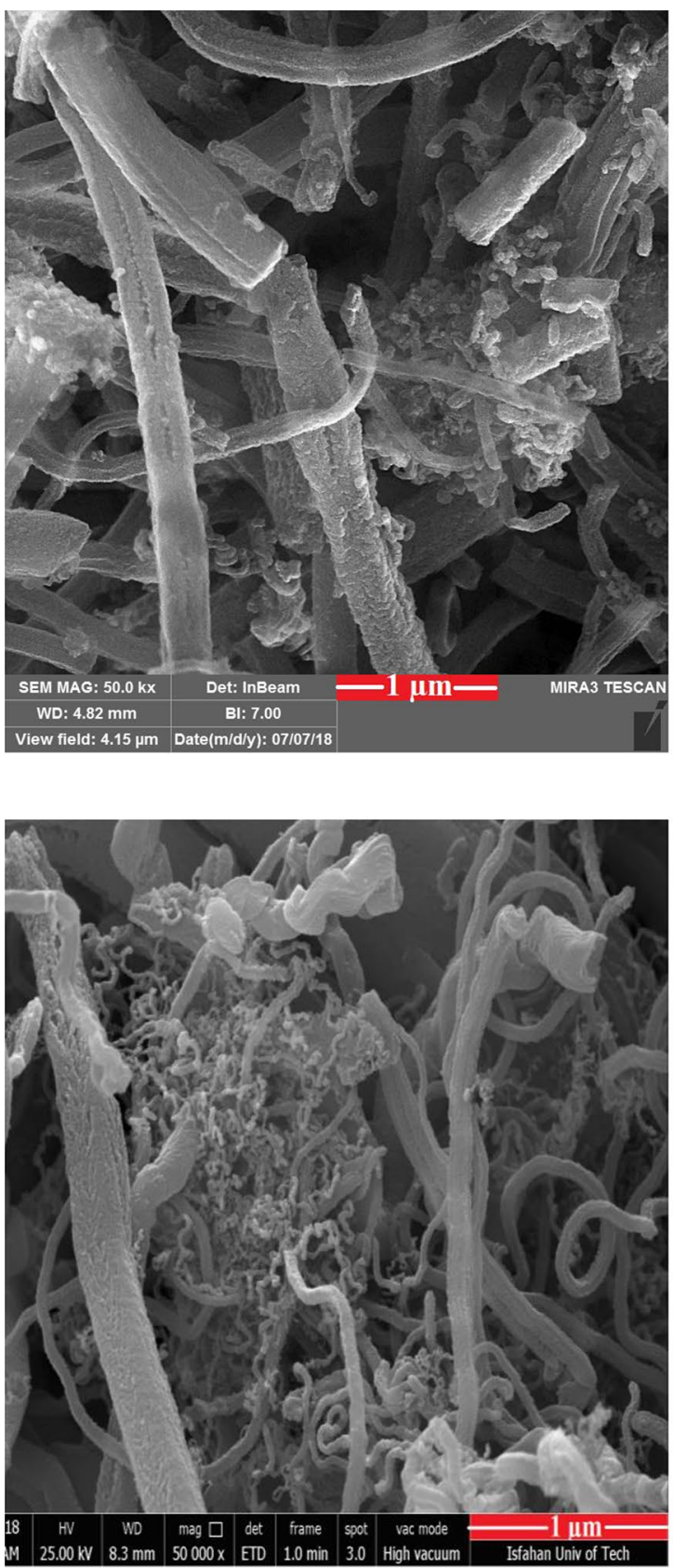

Fig. 1 The FESEM images of all carbon materials prepared at different conditions; top left: SCNFs using $\mathrm{NiFe}_{2} \mathrm{O}_{4}$ as the growth catalyst at $600{ }^{\circ} \mathrm{C}$; top right: SCNFs using $\mathrm{Ni}_{0.5} \mathrm{Zn}_{0.5} \mathrm{Fe}_{2} \mathrm{O}_{4}$ as the growth

were grown from $\mathrm{ZnFe}_{2} \mathrm{O}_{4}$ at $800^{\circ} \mathrm{C}$. Based on the results of these analyses, products $a$ and $b$ have been selected as the most appropriate products.

The EDS analysis was also performed for all products (a-d) and the results were shown in Fig. 2. Besides, the complete results of the EDS analysis are shown in Table S1 in the supporting information. The EDS analyses confirm the existence of sulfur atoms in the structure of these compounds and in all of these analyses, only carbon, sulfur and
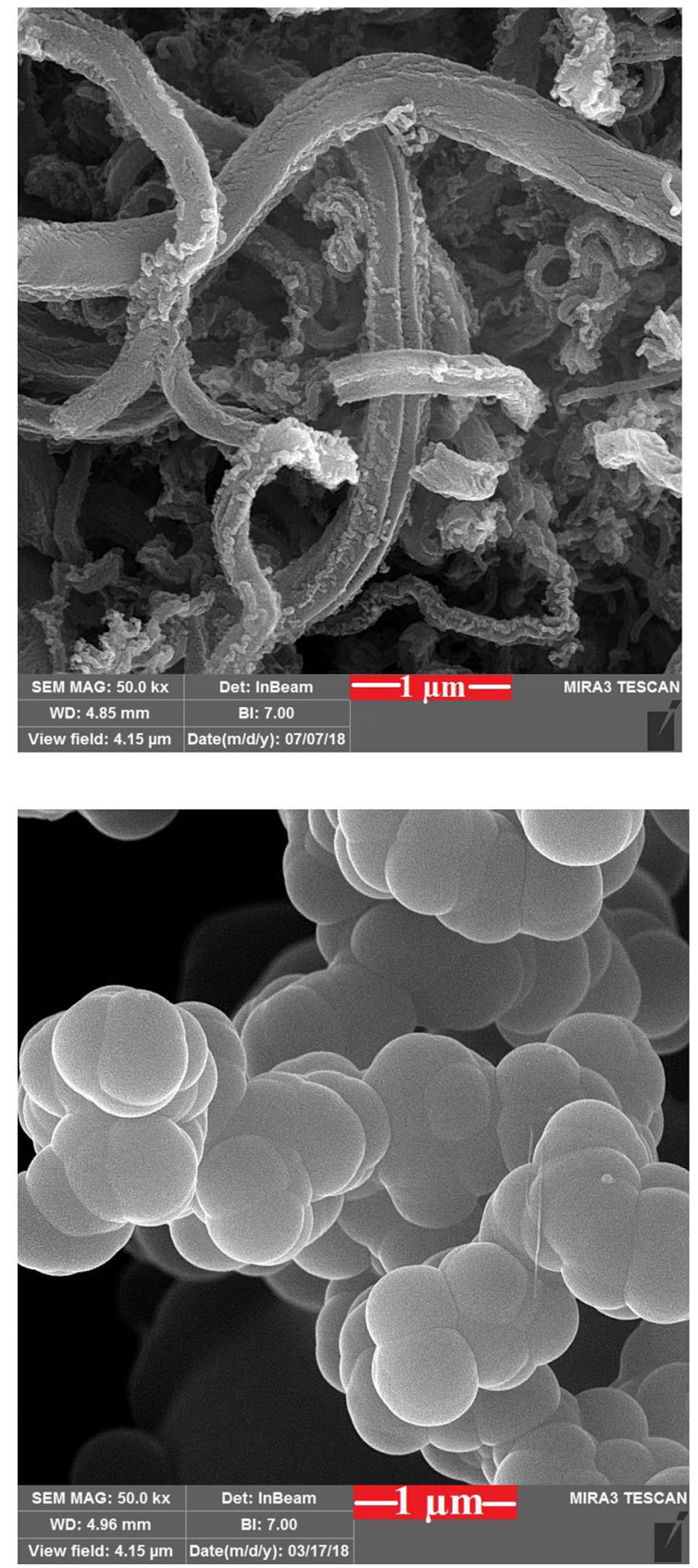

catalyst at $600{ }^{\circ} \mathrm{C}$; below left: $\mathrm{SCNFs}$ using $\mathrm{ZnFe}_{2} \mathrm{O}_{4}$ as the growth catalyst at $600{ }^{\circ} \mathrm{C}$; and below right: carbon spheres using $\mathrm{ZnFe}_{2} \mathrm{O}_{4}$ as the growth catalyst at $800^{\circ} \mathrm{C}$

oxygen (because of the partial surface oxidation) atoms are existed in the structures. Based on these results, the percentage of the sulfur atom in the structure of $\mathrm{SCNFs}$ from $\mathrm{NiF}_{2} \mathrm{O}_{4}$ at $600{ }^{\circ} \mathrm{C}$ (a), SCNFs from $\mathrm{Ni}_{0.5} \mathrm{Zn}_{0.5} \mathrm{Fe}_{2} \mathrm{O}_{4}$ at $600{ }^{\circ} \mathrm{C}$ (b) and $\mathrm{SCNFs}$ from $\mathrm{ZnFe}_{2} \mathrm{O}_{4}$ at $600{ }^{\circ} \mathrm{C}$ (c) and $800^{\circ} \mathrm{C}$ (d) are respectively $7.72,30.46,5.29$, and 24.25 wt. $\%$. The sulfur contents of products $b$ and $d$ are strangely higher than the standard content for the doped products and these products were completely neglected (. Despite

\section{SN Applied Sciences}



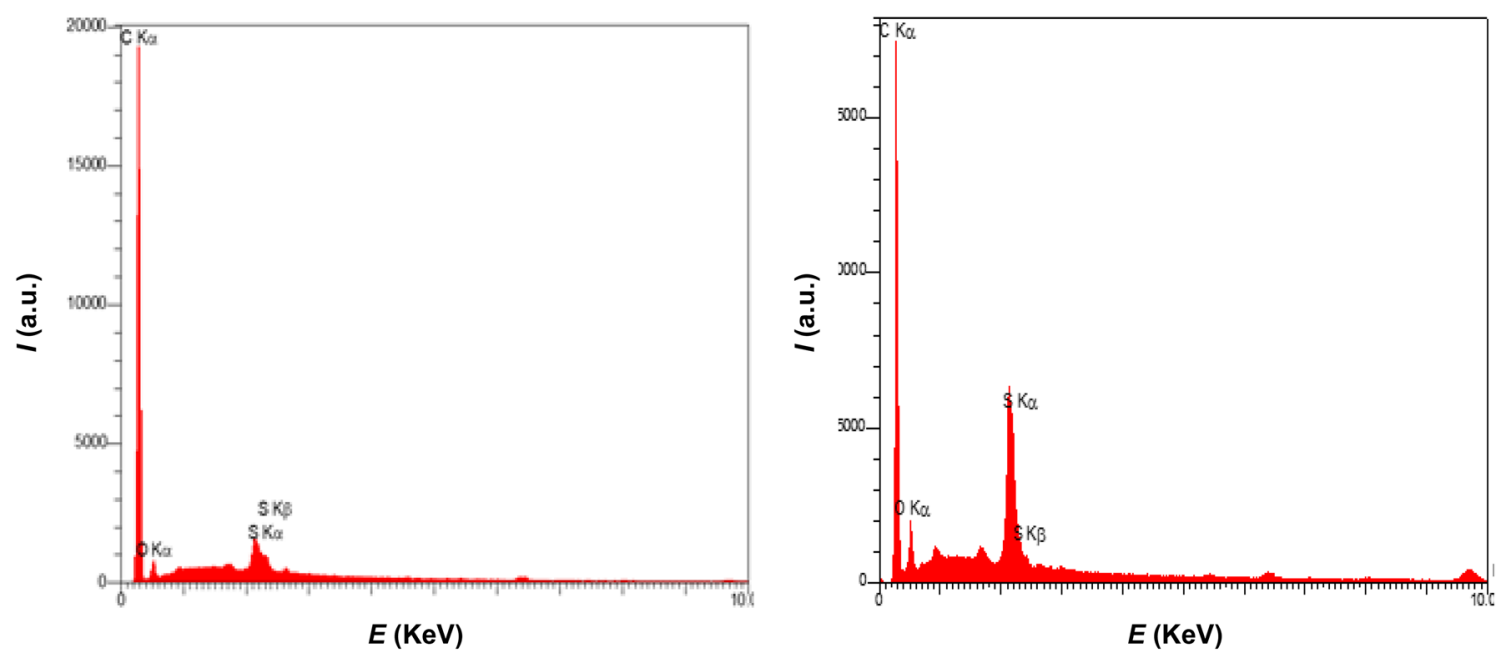

a
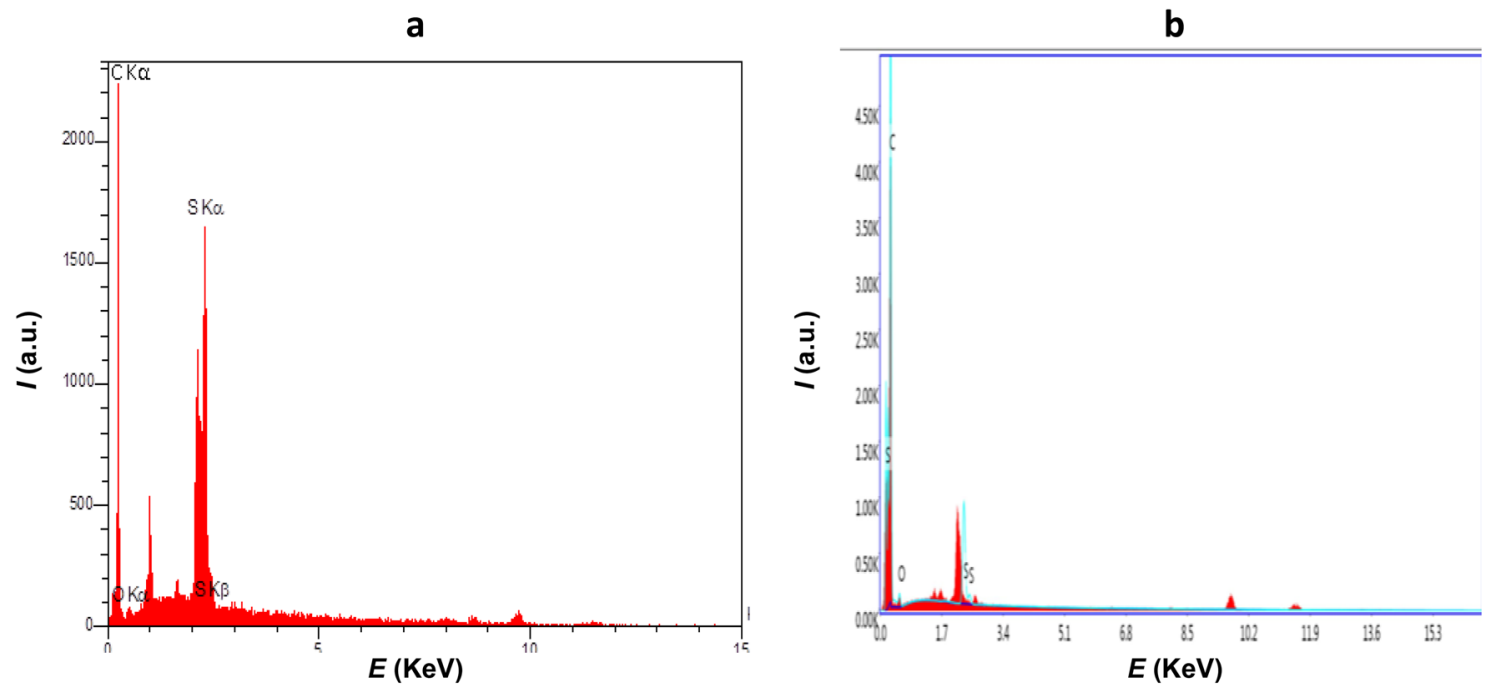

C

d

Fig. 2 The EDS spectra of all carbon materials prepared at different conditions; (a) SCNFs using $\mathrm{NiFe}_{2} \mathrm{O}_{4}$ as the growth catalyst at $600{ }^{\circ} \mathrm{C}$; (b) SCNFs using $\mathrm{Ni}_{0.5} \mathrm{Zn}_{0.5} \mathrm{Fe}_{2} \mathrm{O}_{4}$ as the growth catalyst at

them, products a and c have acceptable sulfur content values and these products are more appropriate than the other products, based on the EDS analyses.

Figure 3 shows the Raman spectra of carbons deposited on the $\mathrm{NiF}_{2} \mathrm{O}_{4}, \mathrm{Ni}_{0.5} \mathrm{Zn}_{0.5} \mathrm{Fe}_{2} \mathrm{O}_{4}$ and $\mathrm{ZnFe}_{2} \mathrm{O}_{4}$. Both $\mathrm{D}$ and $\mathrm{G}$ bands could be observed in these spectra. The $I_{D} / I_{G}$ ratio in product a is less than the other products. Therefore, this product has more appropriate than the other products, based on the Raman analyses.

After the above analyses, product a (SCNFs produces from $\mathrm{NiF}_{2} \mathrm{O}_{4}$ at $600^{\circ} \mathrm{C}$ ) was selected as the best product and further characterizations were made on this structure. Figure 4 shows the TEM micrographs of SCNFs synthesized by $\mathrm{NiF}_{2} \mathrm{O}_{4}$ as a catalyst at $600{ }^{\circ} \mathrm{C}$ (a). The shown images confirm the expected morphology of the SCNFs,
$600{ }^{\circ} \mathrm{C}$; (c) SCNFs using $\mathrm{ZnFe}_{2} \mathrm{O}_{4}$ as the growth catalyst at $600^{\circ} \mathrm{C}$; (d) carbon spheres using $\mathrm{ZnFe}_{2} \mathrm{O}_{4}$ as the growth catalyst at $800^{\circ} \mathrm{C}$

as they previously observed in the FESEM images. The diameters of the produced fibers are $50 \mathrm{~nm}$ on average.

To examine the thermal behavior of the selected product, TGA analysis was employed under the inert atmosphere, because the thermal stability of the new materials is important. Figure 5 shows the TGA curves of the selected product (a). The total weight loss of the product is less than $8 \%$ up to $800{ }^{\circ} \mathrm{C}$, which shows the product's high thermal stability. The obtained diagram does not consist of separate steps, but the weight loss at the temperature range of $50-150{ }^{\circ} \mathrm{C}(1.0 \%)$ could be attributed to the desorption of trapped water. Other losses could be due to surface functional fragmentation, trapped organic parts and surface adsorbed materials. 


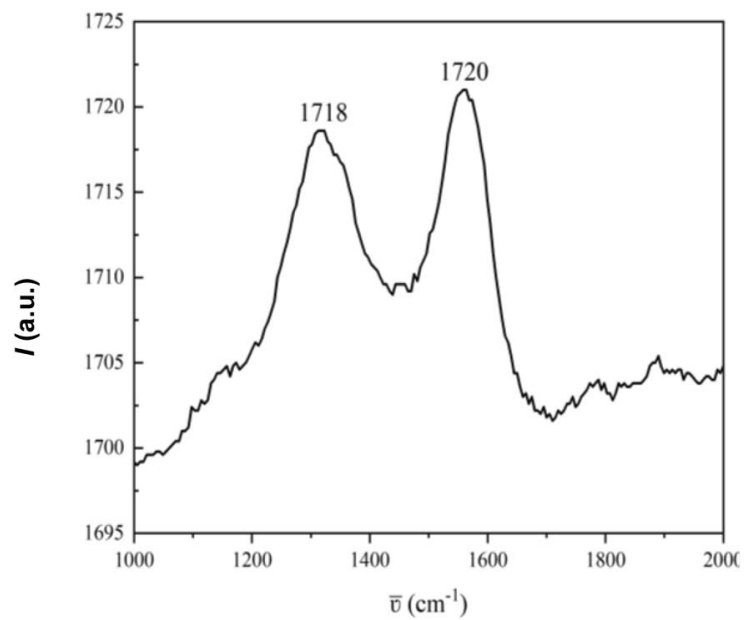

a

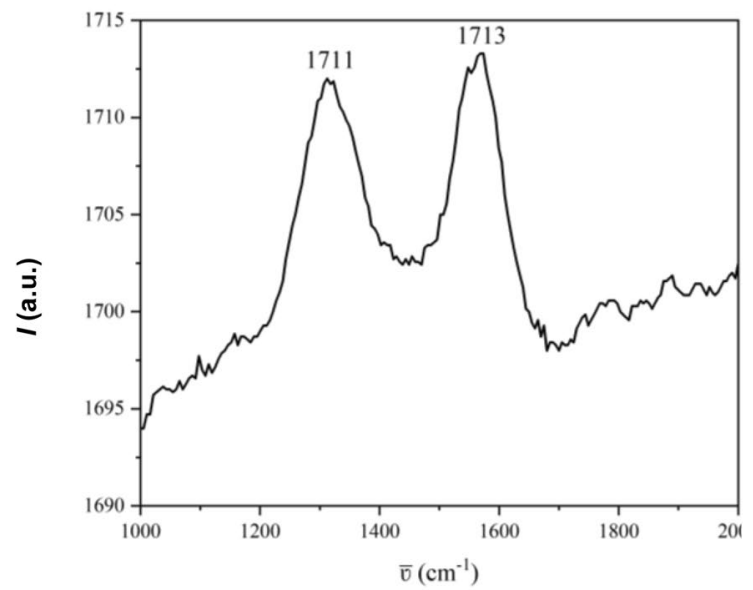

C

Fig. 3 Raman spectra of products (a)-(d). The written numbers are showing the intensities of the bands. (a) SCNFs using $\mathrm{NiFe}_{2} \mathrm{O}_{4}$ as the growth catalyst at $600{ }^{\circ} \mathrm{C}$; (b) SCNFs using $\mathrm{Ni}_{0.5} \mathrm{Zn}_{0.5} \mathrm{Fe}_{2} \mathrm{O}_{4}$ as the

Figure 6 shows the XRD pattern of the product. According to this analysis, the standard pattern for graphite has been observed, according to two peaks at $2 \theta=26^{\circ}$ and $43^{\circ}[36]$. From this pattern, the obtained SCNFs were confirmed to agree with the stacking structure of parallel graphitic layers in SCNFs. The (100) plane shows a peak at $2 \theta=43^{\circ} \mathrm{C}$ and (101) plane showed another peak at $2 \theta=44^{\circ} \mathrm{C}$, that is confirming the structure of SCNFs [36].

The next performed analysis was $\mathrm{X}$-ray photoelectron spectroscopy (XPS) to determine the product's elemental composition and bonding analysis. These experiments' results were depicted in Fig. 7a-e, which shows several peaks related to the presence of oxygen, carbon and sulfur atoms. The existence of these peaks confirms the sulfur doping and carbon structure of the product. Moreover, high-resolution spectra for $\mathrm{C}_{1 \mathrm{~s}}$ (Fig. 7b), O1s (Fig. 7c), sulfur $\mathrm{S}_{2 \mathrm{~s}}$ (Fig. 7d) and sulfur $\mathrm{S}_{2 \mathrm{p}}$ (Fig. 7e) were shown below the major spectrum. These spectra confirm the presence of

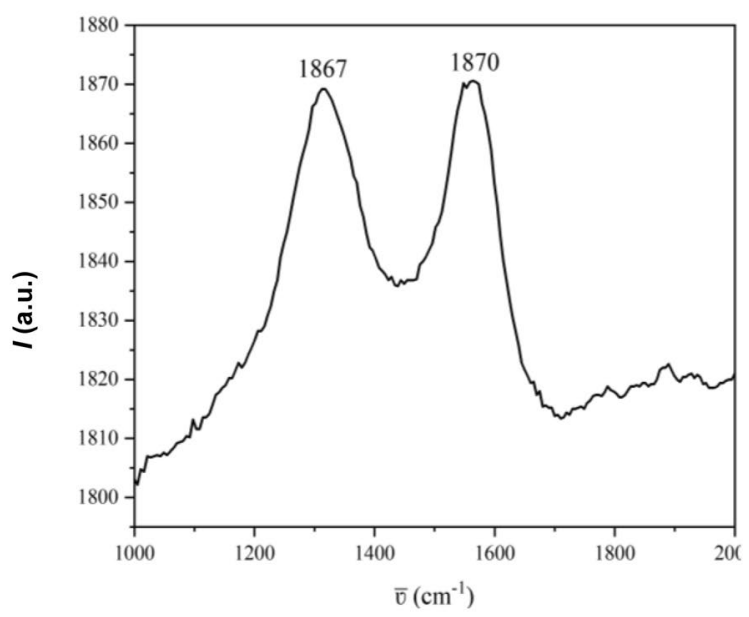

b

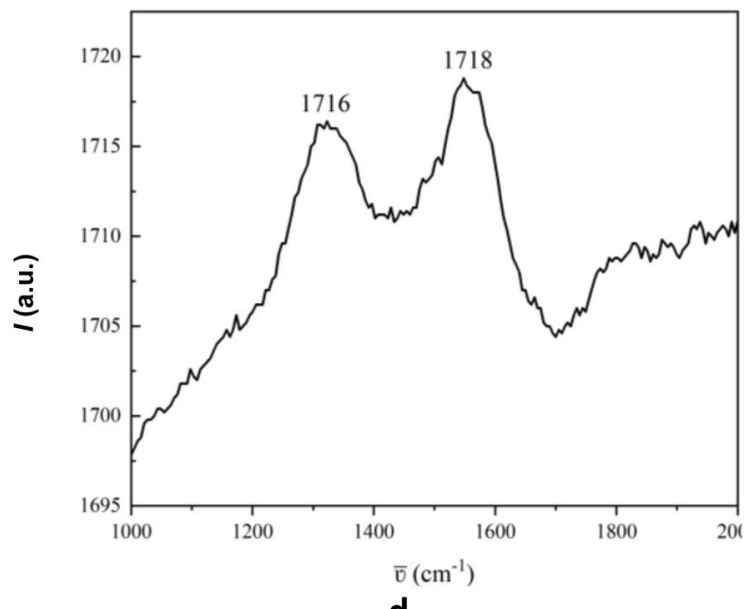

d

growth catalyst at $600{ }^{\circ} \mathrm{C}$; (c) $\mathrm{S} C N F s$ using $\mathrm{ZnFe}_{2} \mathrm{O}_{4}$ as the growth catalyst at $600{ }^{\circ} \mathrm{C} ;$ (d) carbon spheres using $\mathrm{ZnFe}_{2} \mathrm{O}_{4}$ as the growth catalyst at $800^{\circ} \mathrm{C}$

$\mathrm{C}=\mathrm{C} / \mathrm{C}-\mathrm{C}$, related to the conjugated honeycomb lattice, by the observed peak at $282.9 \mathrm{eV}$. Moreover, they confirm the presence of $\mathrm{C}-\mathrm{S}$ bond by observing the peak at $286.5 \mathrm{eV}$, confirming the covalent doping of sulfur atom. The presence of oxygen atom is related to the partial surface oxidation of the product during its purification.

\subsection{Electrochemical deposition of gold nanoparticles on product a}

After the successful synthesis and characterization of the $\mathrm{SCNF}$, the product (a) was electrochemically decorated with gold nanoparticles to prepare the final product for morphine detection. The product was analyzed with FESEM and EDS analyses and the results were depicted in Fig. 8. As it is clear from these images, the deposition of gold nanoparticles was successfully performed and this deposition has not been changed the morphology of the 
Fig. 4 The TEM images of a selected carbon material (SCNFs prepared using $\mathrm{NiF}_{2} \mathrm{O}_{4}$ as a catalyst at $600^{\circ} \mathrm{C}$ )
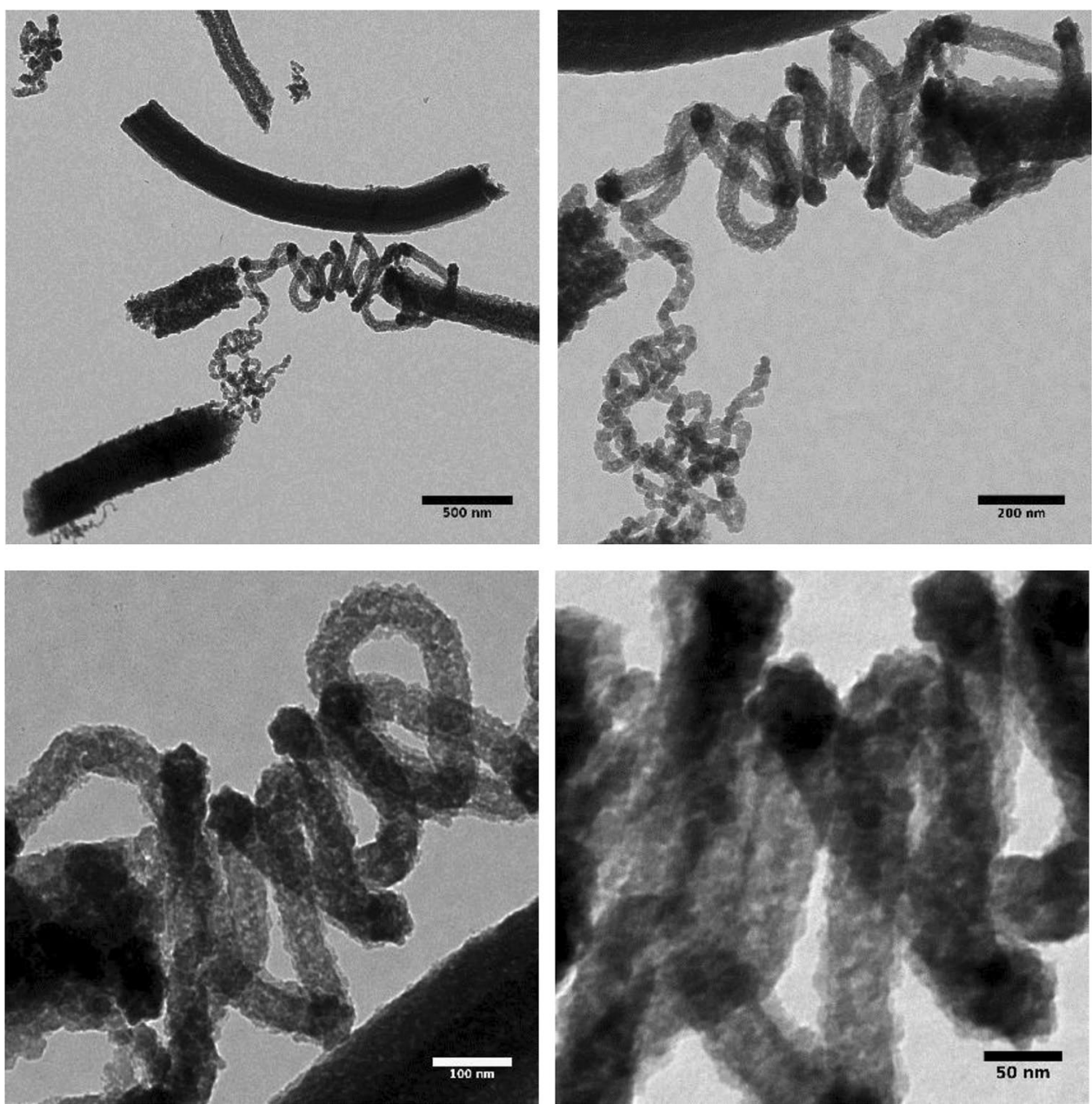

Fig. 5 The TGA diagram of a selected carbon material (SCNFs prepared using $\mathrm{NiF}_{2} \mathrm{O}_{4}$ as a catalyst at $600^{\circ} \mathrm{C}$ )

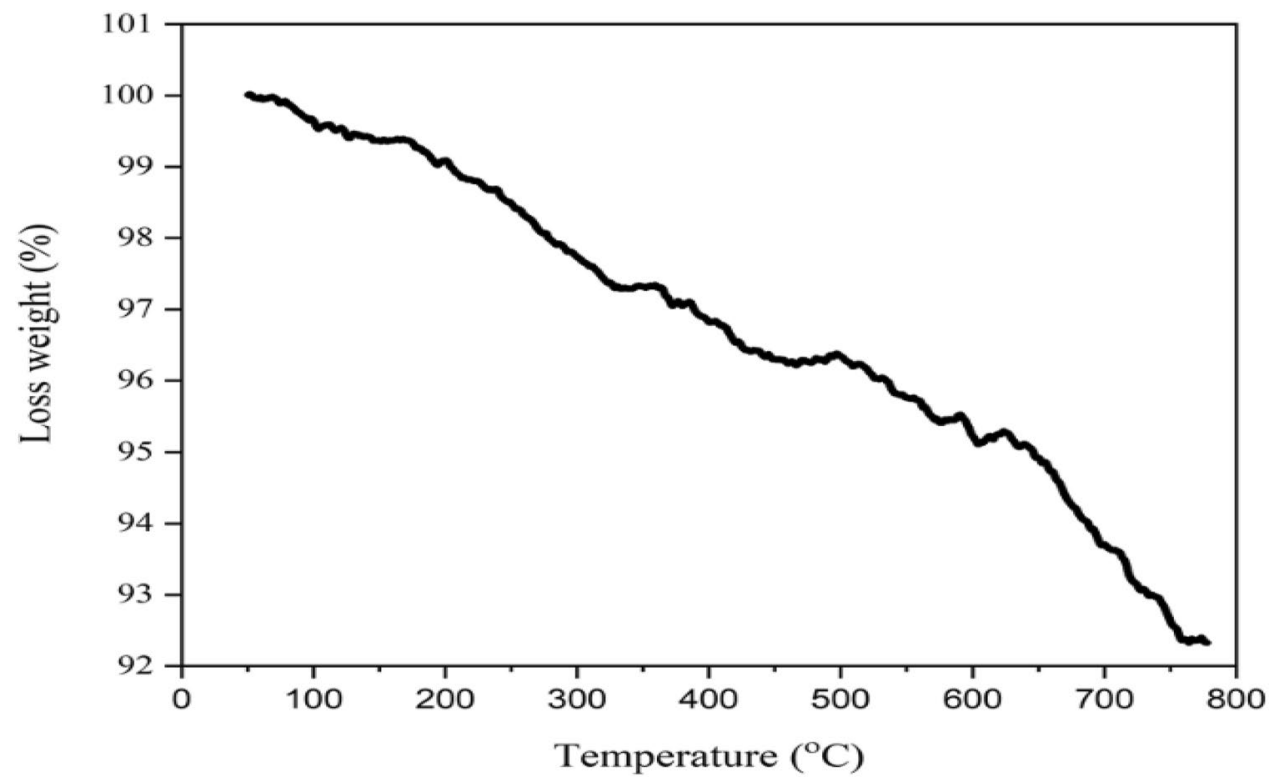




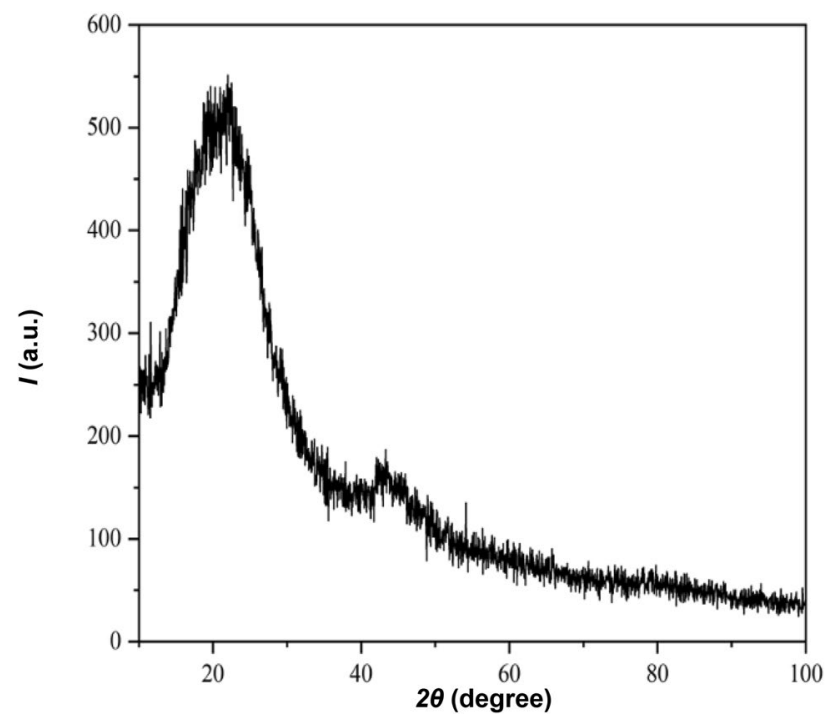

Fig. 6 The XRD pattern of a selected carbon material (SCNFs prepared using $\mathrm{NiF}_{2} \mathrm{O}_{4}$ as a catalyst at $600^{\circ} \mathrm{C}$ )

product. Maintaining the structural form of these fibers reflects their stability during the process. Gold nanoparticles could be observed in these images as small particles on the surface of the fibers. Moreover, the EDS spectrum clearly shows the presence of gold on these structures. Based on the EDS results, the presence of carbon, gold, sulfur, and oxygen in this structure is respectively $94.4,0.4$, 1.4 and $0 \mathrm{wt}$. \%, which shows the decrease of surface oxygen and sulfur content after the decoration of the product with gold.

\subsection{Electrochemical behavior of the final product for morphine sensing}

In the final part of this study, the electrochemical behaviors of product a (SCNFs) and the final product (gold decorated product a, AuNPs/SCNFs) were examined. For this purpose, modified GCE by these products were used in morphine sensing. Since the oxidation of morphine could produce a positive peak, its electrochemical detection is one of the most frequent choices in this respect. This experiment has been performed using the modified GCE with SCNFs to obtain the electrochemical diagrams related to morphine detection. $10 \mathrm{mVs}^{-1}$ scan rate for potential in the range of -1.0 to $1.0 \mathrm{~V}$ of was used in aqueous solution. In Fig. 9, the cyclic voltammograms (CVs), recorded in $1 \mathrm{mM}$ potassium ferrocyanide solution, for simple GCE (A), SCNFs/GCE (B) and AuNPs/SCNFs/GCE (C) have been shown. It can be seen that bare GCE (Fig. 9A) showed a signal for the reversible and diffusion-controlled redox reaction. As is shown in this figure, the oxidation of $\mathrm{Fe}^{2+}$ to $\mathrm{Fe}^{3+}$ at the bare GCE shows an anodic signal at $0.56 \mathrm{~V}$. GCE's modification increases the peak current from 30 to 48 and $68 \mu \mathrm{A}$, respectively for SCNFs/GCE and AuNPs/SCNFs/ GCE. Moreover, the overvoltage of the anodic signal was decreased and the value of potential was changed to the smaller amounts. Obviously, both of these modifications, especially AuNPs/SCNFs/GCE, facilitate the GCE's sensing.

To study the activity of electrodes before the morphine analysis, cyclic voltammetry (CV) studies were performed in Britton-Robinson buffer at room temperature by scanning the potential between -1.0 and $1.0 \mathrm{~V}$ (Fig. 10). Using the buffer $\mathrm{pH}=9.8$, the maximum signal enhancement with the optimum shape of the peak was observed (Fig. 10). In Fig. 11, the CV diagram of simple GCE (A), modified GCE with SCNFs (B) and modified GCE with AuNPs/SCNFs (C) in the presence of $1 \times 10^{-4} \mathrm{M}$ morphine at $\mathrm{pH}=9.8$ were shown. $\mathrm{A}$ clear anodic signal was observed at $0.8 \mathrm{~V}$ in the presence of morphine from the GCE vs. Ag/ $\mathrm{AgCl}$, while no cathodic signal related to the irreversible or reverse processes has been observed (Fig. 11A). The height of the anodic peak with appealing SCNFs/GCE (Fig. 11B) and AuNPs/SCNFs/GCE (Fig. 11C) as the working electrode increased by 7.5 and $13.5 \mu \mathrm{A}$, respectively.

Modifications of GCE with our product have increased the peak current, decreased the value of anodic overvoltage and changed its potential to smaller values (for SCNFs/ GCE (Fig. 11B) and AuNPs/SCNFs/GCE (Fig. 11C), 0.77 and $0.73 \mathrm{~V}$ respectively).

The voltammetric measurements were obtained using square-wave voltammetry (SWV) from bare GCE (A), SCNFs/GCE (B) and AuNPs/SCNFs/GCE (C) versus Ag/AgCl in the presence of $1 \times 10^{-4}$ morphine at $\mathrm{pH}=9.8$ (Fig. 12). The peaks related to the oxidation of morphine were obtained at $0.32,0.38$ and $0.40 \mathrm{~V}$, respectively for SWV at bare GCE (Fig. 12A), SCNFs/GCE (Fig. 12B) and AuNPs/ SCNFs/GCE (Fig. 12C). These characteristics were significantly superior to those obtained for GCE, which indicates the ease of sensing process on the SCNFs/GCE and AuNPs/ SCNFs/GCE. Consequently, the best result was achieved by the electrodeposition of gold nanoparticles on SCNFs/GCE (AuNPs/SCNFs/GCE).

\section{Conclusions}

In this study, a room temperature method has been used for the synthesis of $\mathrm{Ni}, \mathrm{Ni} / \mathrm{Zn}$ and $\mathrm{Zn}$ ferrites nanoparticles. Various shapes for the produced carbon structures have been observed using ferrite nanoparticles as a growth catalyst of the CVD process to prepare of SCNFs. Furthermore, a GCE was modified with the immobilization of synthesized SCNFs. This electrode is also modified by the electrodeposition of gold nanoparticles. The AuNPs/SCNFs-modified GCE showed appropriate 

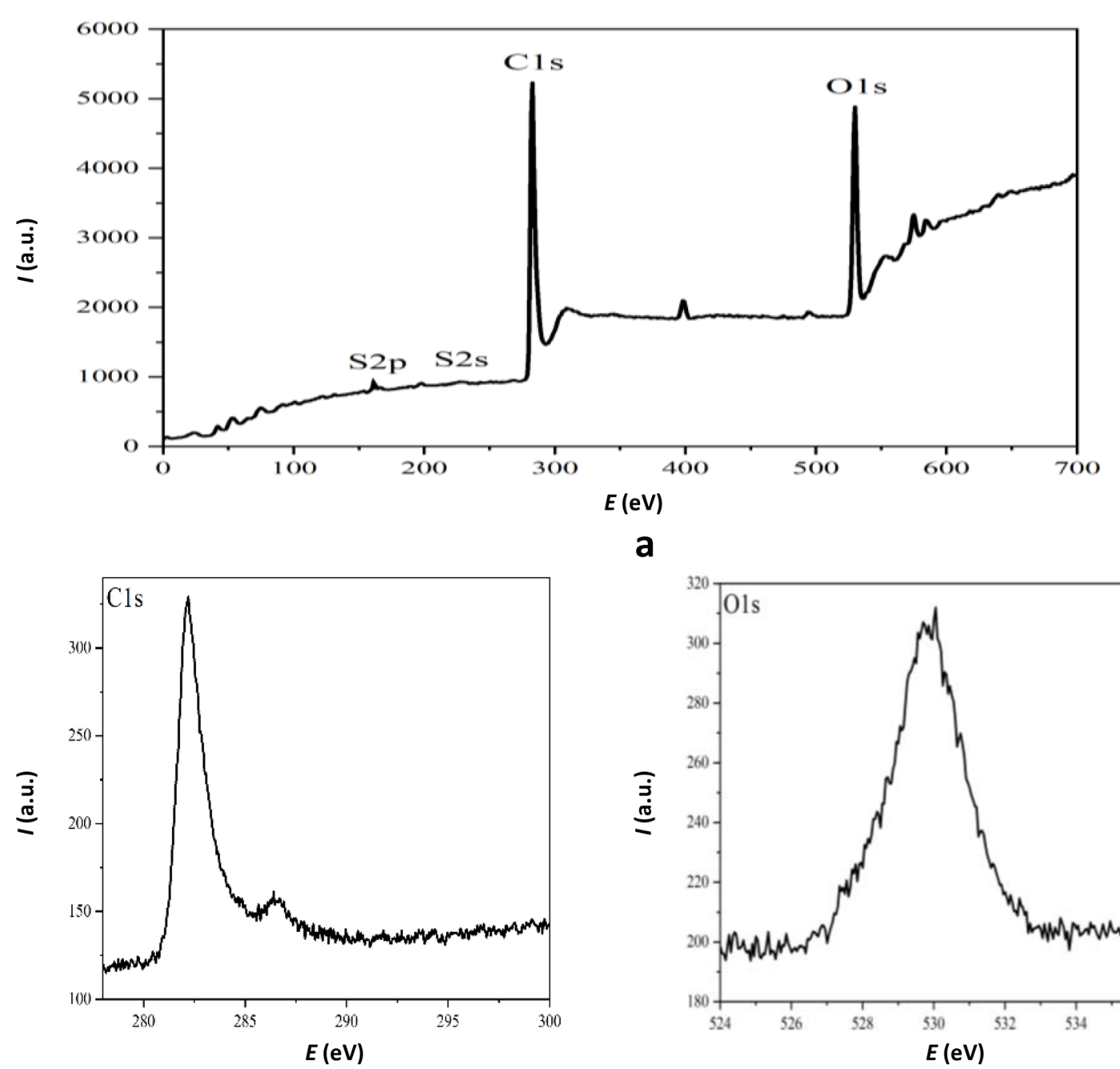

a

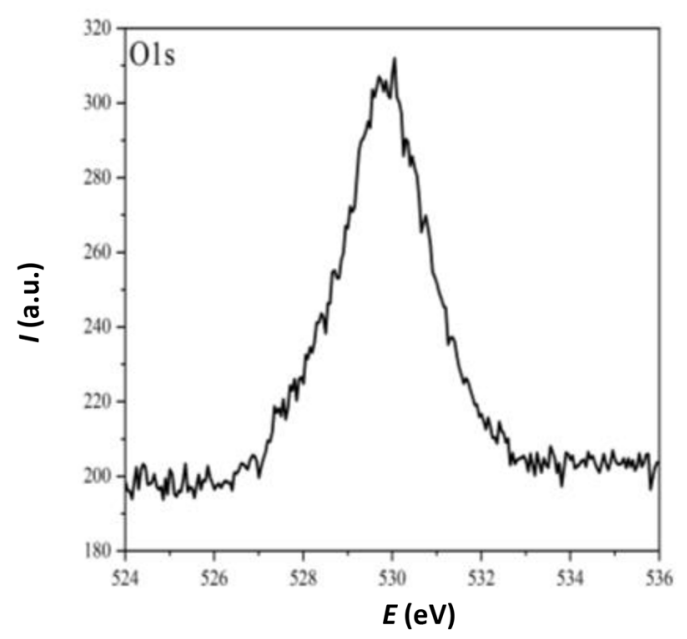

b

C

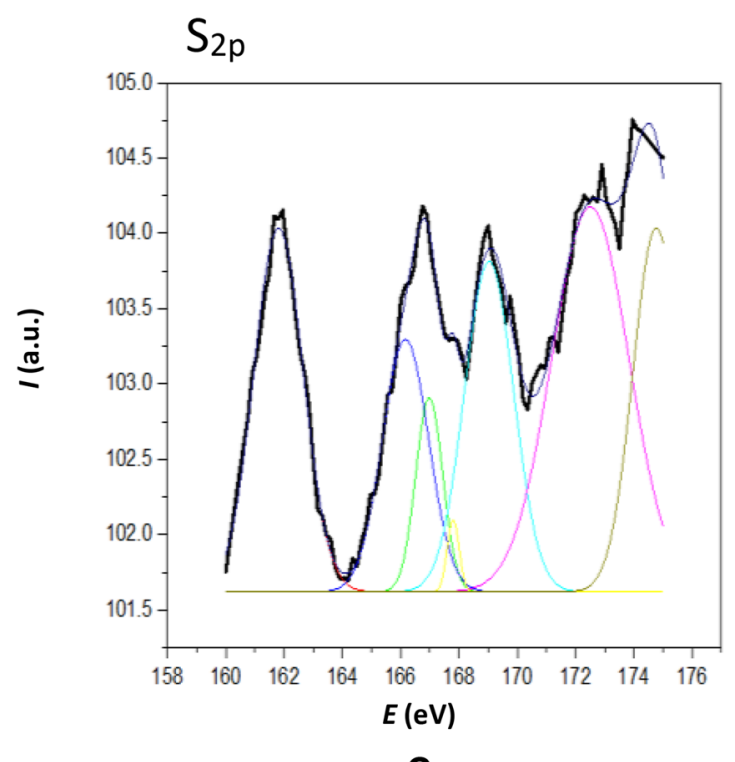

d

e

Fig. 7 The XPS spectra of a selected carbon material ( $\mathrm{SCNFs}$ prepared using $\mathrm{NiF}_{2} \mathrm{O}_{4}$ as a catalyst at $\left.600{ }^{\circ} \mathrm{C}\right) ;(\mathbf{a})$ total spectrum; (b) carbon; (c) oxygen; (d) sulfur $\mathrm{S}_{2 \mathrm{~s}}$ and (e) sulfur $\mathrm{S}_{2 \mathrm{p}}$ 

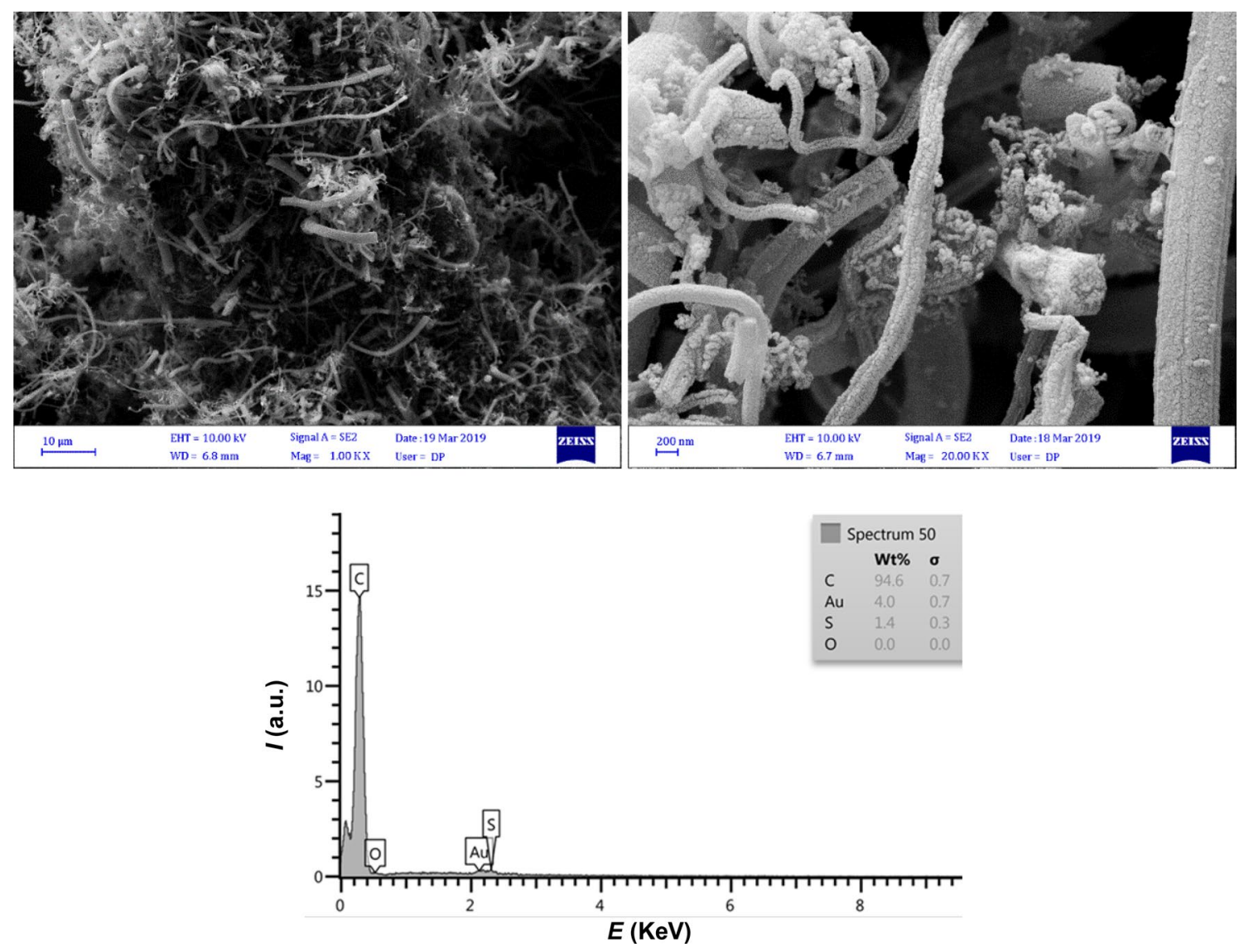

Fig. 8 The FESEM images and EDS analysis of the final product (product a, decorated with gold nanoparticles)

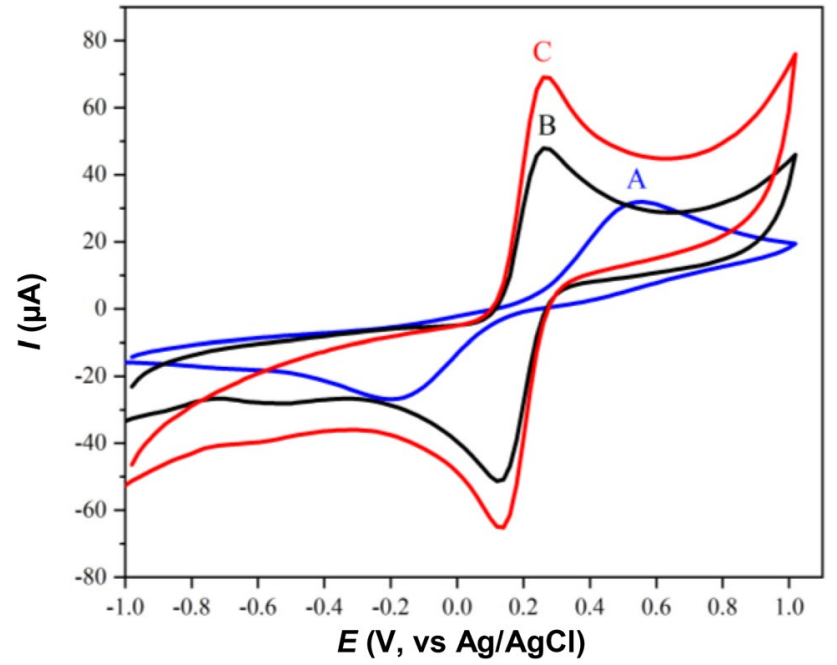

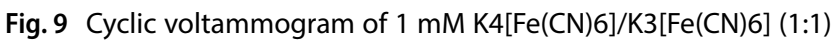
obtained from bare GCE (A), SCNFs/GCE (B) and AuNPs/SCNFs/GCE (C)

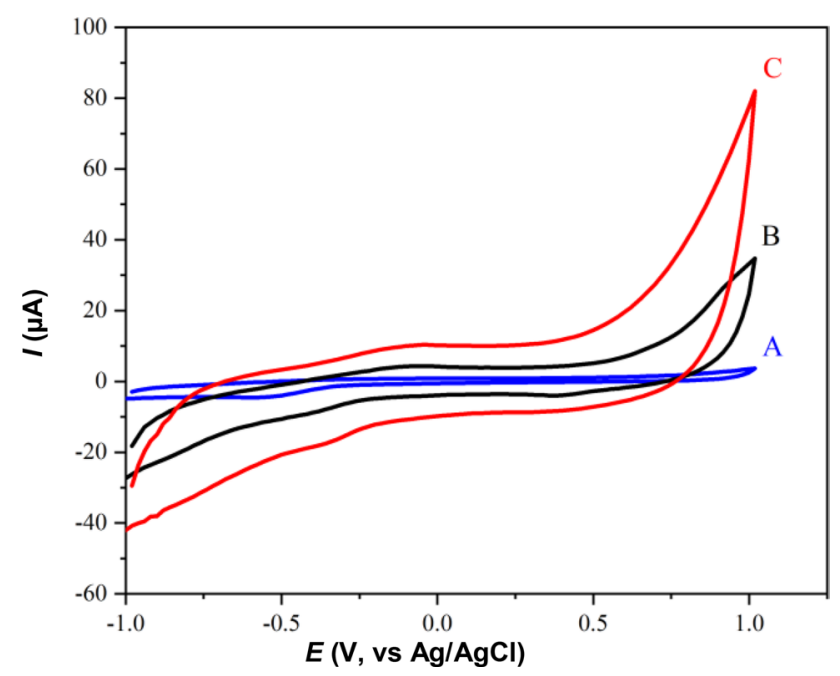

Fig. 10 Cyclic voltammogram from bare GCE (A), SCNFs/GCE (B) and AuNPs/SCNFs/GCE (C) in Britton-Robinson buffer $(\mathrm{pH}=9.8)$

electrochemical behaviors for the oxidation of morphine. It was proved that this electrode has high abilities for detecting morphine, in addition to its promising 


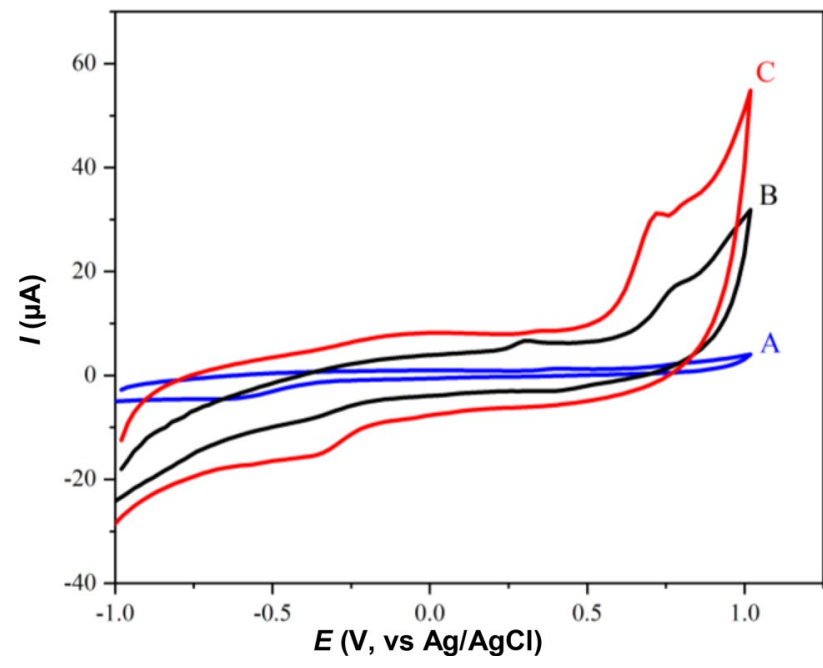

Fig. 11 The obtained cyclic voltammogram from bare GCE (A), SCNFs/GCE (B) and AuNPs/SCNFs/GCE (C) in the presence of $1 \times 10^{-4} \mathrm{M}$ morphine $(\mathrm{pH}=9.8)$

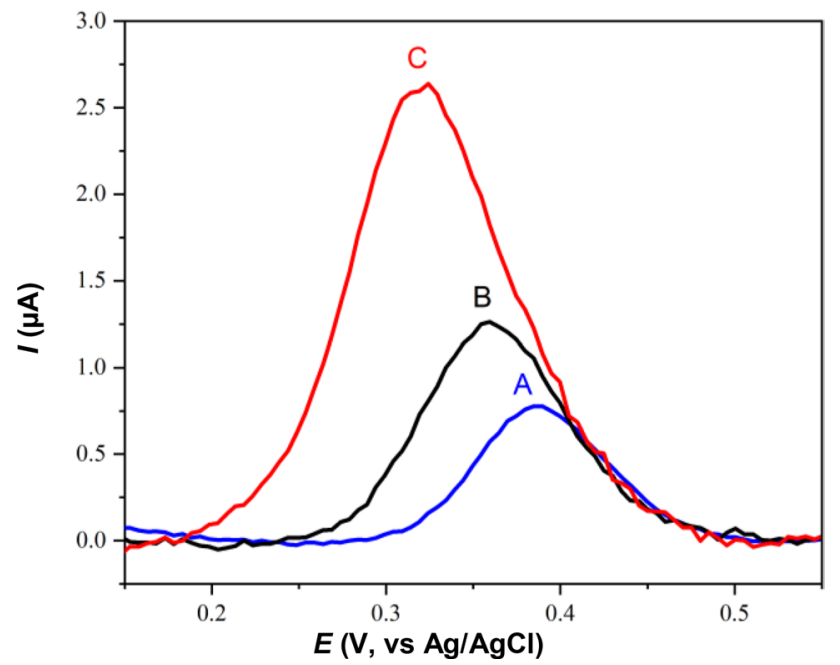

Fig. 12 SWV voltammogram from bare GCE (A), SCNFs/GCE (B) and AuNPs/SCNFs/GCE (C) in the presence of $1 \times 10^{-4} \mathrm{M}$ morphine $(\mathrm{pH}=9.8)$

stability. The most important benefits of the presented methodology are its simplicity and fast detection.

Acknowledgements We have special thanks to Professor Martin Beyer for helping us to provide research facilities for this work.

\section{Compliance with ethical standards}

Conflict of interest The authors clearly stated that there is not and conflict of interests related to this work.

\section{References}

1. Romero A, Garrido A, NietoMárquez A, de la Osa AR, de Lucas $A$, Valverde JL (2007) The influence of operating conditions on the growth of carbon nanofibers on carbon nanofibersupported nickel catalysts. Appl Catal A Gen 319:246-258

2. Rodriguez NM (1993) A review of catalytically grown carbon nanofibers. J Mater Res 8:3233-3250

3. Huang J, Liu Y, You T (2010) Carbon nanofiber based electrochemical biosensors: A review. Anal Methods 2:202-211

4. Jong KPD, Geus JW (2000) Carbon nanofibers, catalytic synthesis and applications. Catal Rev Sci Eng 42:481-510

5. Mohammadi F, Tavakol H (2018) Synthesis of phosphorus doped carbon nanotubes using chemical vapor deposition. Fullerenes Nanotubes Carbon Nanostruct 26:218-225

6. Hazra S, Ghosh NN (2014) Preparation of nanoferrites and their applications. J Nanosci Nanotechnol 14:1983-2000

7. Schwertmann U, Cornell RM (2000) Iron oxides in the laboratory, preparation and characterization. WileyVCH

8. Yamada Y, Hosono Y, Murakoshi N, Higashi N, Ichioka H, Miyake T, Ikenaga N, Suzuki T (2006) Carbon nanofiber formation on iron group metal loaded on SiO2. Diam Relat Mater 15:1080-1084

9. Takenaka S, Kobayashi S, Ogihara H, Otsuka K (2003) Ni/SiO2 catalyst effective for methane decomposition into hydrogen and carbon nanofiber. J Catal 217:79-87

10. Toebes $M(2002)$ Impact of the structure and reactivity of nickel particles on the catalytic growth of carbon nanofibers. Catal Today 76:33-42

11. Feng L, Xie N, Zhong J (2014) Carbon nanofibers and their composites: A review of synthesizing, properties and applications. Materials 7:3919-3945

12. Esconjauregui S, Whelan CM, Maex K (2009) The reasons why metals catalyze the nucleation and growth of carbon nanotubes and other carbon nanomorphologies. Carbon 47:659-669

13. Taber DF, Neubert TD, Rheingold AL (2002) Synthesis of morphine. J Am Chem Soc 124:12416-12417

14. Atta NF, Galal A, AbdelGawad FM, Mohamed EF (2014) Electrochemical morphine sensor based on gold nanoparticles metalphthalocyanine modified carbon paste electrode. Electroanalysis 27:415-428

15. Lee HM, Lee CW (1991) Determination of morphine and codeine in blood and bile by gas chromatography with a derivatization procedure. J Anal Toxicol 15:182-187

16. Hyötylainen T, KeskiHynnilä H, Riekkola ML (1997) Determination of morphine and its analogues in urine by online coupled reversedphase liquid chromatographygas chromatography with online derivatization. J Chromatogr A 771:360-365

17. Meng QC, Cepeda MS, Kramer T, Zou H, Matoka DJ, Farrar J (2000) Highperformance liquid chromatographic determination of morphine and its 3 and Gglucuronide metabolites by twostep solidphase extraction. J Chromatogr B 742:115-123

18. Yeh WM, Ho KC (2005) Amperometric morphine sensing using a molecularly imprinted polymermodified electrode. Anal Chim Acta 542:76-82

19. Soares ME, Seabra V, Bastos MD (1992) Comparative study of different extractive procedures to quantify morphine in urine by HPLC-UV. J Liq Chromatogr 15:1533-1541

20. Dams R, Benijts T, Lambert WE, Leenheer APD (2002) Simultaneous determination of in total 17 opium alkaloids and opioids in blood and urine by fast liquid chromatography. J Chromatogr B 773:53-61

21. Pulgarn JAM, Bermejo LFG, Gallego JML, Garca MNS (2008) Simultaneous stoppedflow determination of morphine and naloxone by timeresolved chemiluminescence. Talanta 74:1539-1546 
22. Zhang XX, Li J, Gao J, Sun L, Chang WB (2000) Determination of morphine by capillary electrophoresis immunoassay in thermally reversible hydrogelmodified buffer and laserinduced fluorescence detection. J Chromatogr A 895:1-7

23. Li F, Song J, Gao D, Zhang Q, Han D, Niu L (2009) Simple and rapid voltammetric determination of morphine at electrochemically pretreated glassy carbon electrodes. Talanta 79:845-850

24. Ayed Z, Cuvillier L, Dobhal G, Goreham RV (2019) Electroporation of outer membrane vesicles derived from Pseudomonas aeruginosa with gold nanoparticles. SN Appl Sci 1:1600

25. Sangeetha NS, Narayanan SS (2019) Amperometric H2O2 senor based on gold nanoparticles/poly (celestine blue) nanohybrid film. SN Appl Sci 1:732

26. Mukherjee $M$, Purkayastha $P$ (2020) The influence of gold nanoparticles on reduction of [Co (NH3)5Br](NO3)2 by iron (II). SN Appl Sci 2:1

27. Hashmi ASK, Hutchings GJ (2006) Gold catalysis. Angew Chem Int Ed 45:7896-7936

28. Dhand V, Mittal G, Rhee KY, Park SJ (2017) Synthesis and comparison of different spinel ferrites and their catalytic activity during chemical vapor deposition of polymorphic nanocarbons. Int J Eng Manage 4:441-451

29. Hassani F, Tavakol H, Keshavarzipour F, Javaheri A (2016) A simple synthesis of sulfurdoped graphene using sulfur powder by chemical vapor deposition. RSC Adv 6:2715-2716

30. Hassani F, Tavakol H (2018) Synthesis of sulfur-doped carbon nanotubes from sulfur powder using chemical vapor deposition. Fullerenes Nanotubes Carbon Nanostruct 26:479-486
31. Tavakol H, Zhiani M, Shareifyan-ghahfarokhi F Gold-decorated sulfur-doped carbon nanotubes as electrocatalyst in hydrogen evolution reaction. Gold Bull. https://doi.org/10.1007/s1340 4-020-00275-0

32. Bao N, Shen L, Wang Y, Padhan P, Gupta A (2007) A facile thermolysis route to monodisperse ferrite nanocrystals. J Am Chem Soc 129:12374-12375

33. Velmurugan K, Venkatachalapathy VSK, Sendhilnathan S (2010) Synthesis of nickel zinc iron nanoparticles by coprecipitation technique. Mater Res 13:299-303

34. Liu $H$, Zhu H, Yang $H$ (2013) A low temperature synthesis of nanocrystalline spinel $\mathrm{NiFe} 2 \mathrm{O} 4$ and its electrochemical performance as anode of lithiumion batteries. Mater Res Bull 48:1587-1592

35. Pradhan GK, Padhi DK, Parida KM (2013) Fabrication of aFe2O3 nanorod/RGO composite: A novel hybrid photocatalyst for phenol degradation. ACS Appl Mater Interfaces 5:9101-9110

36. Ren J, Li FF, Lau J, GonzálezUrbina L, Licht S (2015) One-pot synthesis of carbon nanofibers from CO2. Nano Lett 15:6142-6148

Publisher's Note: Springer Nature remains neutral with regard to jurisdictional claims in published maps and institutional affiliations. 